\title{
PREFERENTIAL IMMUNOHISTOCHEMICAL LOCALIZATION OF VASOACTIVE INTESTINAL POLYPEPTIDE (VIP) IN THE SACRAL SPINAL CORD OF THE CAT: LIGHT AND ELECTRON MICROSCOPIC OBSERVATIONS ${ }^{1}$
}

\author{
CHRISTOPHER N. HONDA, ${ }^{*}{ }^{2}$ MIKLÓS RÉTHELYI, $\|$ AND PETER PETRUSZ $§$ \\ ${ }^{*}$ Neurobiology Program and Departments of $\ddagger$ Physiology and $\S$ Anatomy, University of North Carolina, Chapel Hill, North \\ Carolina 27514 and || 2nd Department of Anatomy, Semmelweis University, Medical School, Budapest, Hungary
}

Received January 3, 1983; Revised April 27, 1983; Accepted May 3, 1983

\begin{abstract}
In the present study we have employed immunoperoxidase techniques to investigate the distribution of vasoactive intestinal polypeptide (VIP)-like immunoreactivity in the spinal cord and sensory ganglia of the cat. The spinal distribution of VIP-containing neuronal processes was also compared with that of substance P (SP), somatostatin (SOM), and cholecystokinin-8 (CCK) at lumbar, sacral, and coccygeal levels.

At sacral levels, VIP was found to be contained in small and medium-sized primary sensory neurons and in dorsal rootlets. Deafferentation, by either ganglionectomy or dorsal rhizotomy, resulted in a nearly complete loss of VIP immunoreactivity in the spinal cord. The spinal distribution of VIP fibers and terminals was most dense and extensive in sacral segments. Forming a thin shell around the dorsal horn, collaterals, apparently originating from Lissauer's tract, projected either medially or laterally through lamina I. Laterally, many VIP axons terminated in lateral laminae V to VII. Others projected further through the neck of the dorsal horn to medial lamina V and the gray matter near the central canal. Medially, VIP axons descended through lamina I to expand into terminal fields in the posterior commissure and medial lamina $\mathrm{V}$.

At the ultrastructural level, VIP-like immunoreactivity was found in dense core vesicles within axonal enlargements containing both large dense core and smaller clear round vesicles. Synaptic connections were infrequently observed but, when encountered, were of the simple axodendritic type.

The spinal distribution of VIP-containing fibers was remarkably similar to that reported for pelvic nerve visceral afferents, both in termination patterns within the spinal gray matter and in localization to the sacral cord. The density of SP-, SOM-, and CCK-containing fibers and terminals was constant at all levels examined (L4 to Co4). In marked contrast, the distribution of VIP fibers, much like that of pelvic nerve afferents, was mostly confined to sacral segments.

Thus, although SP, SOM, and CCK may be contained within a population of sacral visceral afferents, they must be common to afferent systems in other segments as well. VIP, however, appears to be preferentially contained within pelvic visceral afferent fibers confined mostly to sacral segments.
\end{abstract}

Although originally isolated from the gastrointestinal tract (Said and Mutt, 1970), vasoactive intestinal poly-

\footnotetext{
${ }^{1}$ The National Institute of Neurological and Communicative Disorders and Stroke of the United States Public Health Service provided support for the project (Grant NS 10321) and facilities (Grant NS 14899), as well as a predoctoral fellowship for C. N. H. (Grant NS 017166) and support for P. P. (Grant NS 14904). Portions of this work were begun while $M$. R. held a visiting faculty position at the University of North Carolina; this collaboration was sponsored by the Hungarian Institute of Cultural Relations (Kulturális Kapcsolatok Intézete) and the U. S. National Science Foundation.
}

peptide (VIP), a compound containing 28 amino acid residues, was soon discovered in both neural cell lines and nervous tissue (Bryant et al., 1976; Larsson et al., 1976; Said and Rosenberg, 1976). Subsequent studies

\footnotetext{
We wish to thank Dr. E. R. Perl for providing guidance and laboratory facilities. We are grateful to Carol Metz for the preparation of histological material and Margaret 'laylor and Rozália Fervágner for expert technical assistance.

${ }^{2}$ To whom correspondence should be addressed, at Neurobiology Curriculum, University of North Carolina, 454 MacNider 202H, Chapel Hill, NC 27514.
} 
have demonstrated a widespread, but selective, distribution of immunoreactive VIP in both the central and peripheral nervous systems (Fuxe et al., 1977; Emson et al., 1978, 1979; Besson et al., 1979; Giachetti and Said, 1979; Larsson, et al., 1979; Loren et al., 1979; Costa et al., 1980; Hökfelt et al., 1980; Gibson et al., 1981; Yaksh et al., 1982).

Our initial investigations of the immunohistochemical distribution of VIP in the spinal cord were prompted by brief but consistent descriptions of the presence of VIP fibers in the superficial layers of the spinal dorsal horn and the gray matter surrounding the central canal (Gibson et al., 1981; Hökfelt et al., 1982). The superficial dorsal horn has been shown to play a major role in nociceptive function (Christensen and Perl, 1970; Kumazawa and Perl, 1976), and more recently, the region around the central canal has been suggested to process noxious information (Honda and Perl, 1981). The reported distribution of VIP within these two spinal regions, and the cellular localization of VIP in some smalldiameter sensory neurons (Lundberg et al., 1978), suggested a possible nociceptive function for VIP-containing neuronal elements in the spinal cord.

Utilizing both light and electron microscopic immunohistochemical techniques, we have investigated the origin and distribution of VIP-like immunoreactivity in the lumbar, sacral, and coccygeal spinal segments of the cat. Our results demonstrate the presence of VIP immunoreactivity in dense core vesicles of primary afferent fibers of the sacral spinal cord and reveal a much wider distribution within the gray matter than has been described previously. The nearly complete restriction of VIP fibers to the sacral segments is in agreement with recent preliminary reports (Basbaum and Glazer, 1982. Kawatani et al., 1982). It is suggested that, unlike substance $P$, somatostatin, or cholecystokinin, VIP-containing fibers may be preferentially associated with an afferent system, such as the pelvic visceral nerves, which is restricted to the sacral spinal cord. Portions of these data have been presented previously in abstract form (Honda, 1982).

\section{Materials and Methods}

Tissue preparation. Deeply anesthetized (sodium pentobarbital; $40 \mathrm{mg} / \mathrm{kg}$ ) adult cats of both sexes were perfused through the carotid artery with $0.4 \%$ paraformaldehyde in $0.075 \mathrm{M}$ phosphate-buffered saline (PBS) at $37^{\circ} \mathrm{C}$. This was followed by $4 \%$ paraformaldehyde for light microscopy (LM) or 3 to $4 \%$ paraformaldehyde/ $0.2 \%$ glutaraldehyde for electron microscopy (EM), both in $0.1 \mathrm{M}$ PBS at $4^{\circ} \mathrm{C}$. Spinal segments and ganglia were carefully excised and postfixed in 2 to $4 \%$ paraformaldehyde for 6 to $12 \mathrm{hr}$ at $4^{\circ} \mathrm{C}$, then rinsed with frequent changes in $0.01 \mathrm{M} \mathrm{PBS}$ at $4^{\circ} \mathrm{C}$ for at least $24 \mathrm{hr}$. In some cases, animals were pretreated with a subdural application of colchicine $(10 \mu \mathrm{l} ; 2$ to $4 \%$ in saline) and maintained anesthetized for $24 \mathrm{hr}$ before perfusion.

Immunohistochemical procedures. Both transverse and horizontal Vibratome sections $(50 \mu \mathrm{m})$ from spinal segments lumbar 4 through coccygeal 4 were collected in PBS. To promote the penetration of reagents, the $\mathrm{LM}$ sections were then subjected to a series of ethanols $(50 \%$,
$10 \mathrm{~min} ; 70 \%, 15 \mathrm{~min} ; 50 \%, 10 \mathrm{~min}$; PBS). The sections destined for EM analysis were pretreated with a less harsh series of ethanols (10-25-50-25-10\%) for $2 \mathrm{~min}$ each before being returned to PBS.

All sections were then placed in $2 \%$ normal sheep serum (NSS) in PBS (10 $\mathrm{min})$ before being incubated with primary antisera at $4^{\circ} \mathrm{C}$ for approximately $24 \mathrm{hr}$. Following this incubation, sections were processed according to the unlabeled antibody (peroxidase-antiperoxidase; PAP) method (Sternberger, 1979), using modifications previously described (Petrusz et al., 1975). This consisted of sequential applications of sheep anti-rabbit gamma globulin (Antibodies Inc., Davis, CA) and PAP complex (Sternberger-Meyer Immunocytochemicals, Jarrettsville, MD), both used at dilutions of 1:100 for 20 min at room temperature. Subsequent to the PAP incubation, sections were reacted with $0.075 \% 3,3^{\prime}$-diaminobenzidine tetrahydrochloride monohydrate (DAB; Aldrich Chemical Co., Milwaukee, WI) and $0.002 \% \mathrm{H}_{2} \mathrm{O}_{2}$ in Tris buffer for $10 \mathrm{~min}$. Following 10 -min rinses, first in Tris buffer and then in PBS, LM sections were mounted on slides, dried, sometimes counterstained, cleared, and coverslipped; EM sections were processed as described below. Most of the data presented are from Vibratomesectioned material. The results have been confirmed with the PAP technique in both frozen and paraffin-embedded material.

Antisera employed. All primary antisera were produced in rabbits and diluted in PBS $(0.1 \mathrm{M}) / \mathrm{NSS}(1 \%) / \mathrm{NaN}_{3}$ $(0.1 \%)$. An antiserum raised against unconjugated synthetic porcine VIP (No. 676) was kindly supplied by Calbiochem-Behring Corp. (Palo Alto, CA) and was used at dilutions of $1: 4000$ to $1: 8000$. The antiserum raised against thyroglobulin-conjugated somatostatin (No. 669) was generously provided by S. Reichlin (New England Medical Center, Boston, MA). This serum was used in this study at dilutions of $1: 4000$ to $1: 6000$. Antisera directed against substance $P$ (No. 353) and cholecystokinin $26-33$ (CCK-8; No. 7183), both conjugated to hemocyanin, were obtained commercially from Immunonuclear Corp. (Stillwater, MN) and utilized at dilutions of 1:1000 to $1: 3000$.

Control absorptions. The specificity of each primary antiserum was tested by preabsorption with a graded series of concentrations $(0.015$ to $150 \mu \mathrm{g}$ of antigen $/ \mathrm{ml}$ of antiserum at working dilution) of each of the following antigens: synthetic porcine VIP (Peninsula Laboratories, San Carlos, CA), substance P (Beckman Instruments, Inc., Palo Alto, CA), somatostatin (Sigma Chemical Co., St. Louis, MO), and cholecystokinin 26-33, sulfated (Sigma).

Surgical deafferentation. Unilateral deafferentation of the sacral cord was accomplished under sterile conditions in anesthetized animals (sodium pentobarbital; $35 \mathrm{mg}$ / $\mathrm{kg}$ ). The contribution of dorsal root afferent fibers to VIP immunoreactivity was assessed by a dorsal rhizotomy. The dorsal roots ( $\mathrm{S} 1$ to $\mathrm{S} 3$ ) were visualized and sectioned unilaterally through a partial laminectomy of the L6 and L7 vertebrae. A unilateral ganglionectomy was performed to evaluate the possible contribution of ventral root afferents to VIP immunostaining. Sacral ganglia (S1 to S3) were visualized and excised through 
an opening made in the dorsolateral aspect of the sacrum. Both types of experimental animals were allowed to survive for 12 days following surgery.

Electron microscopy. Subsequent to immunohistochemical processing, Vibratome sections were flat embedded for EM as described by Metz et al. (1983). Briefly, the sections were reacted in a phosphate-buffered $2 \%$ osmium tetroxide solution for $40 \mathrm{~min}$, washed in PBS, dehydrated in graded ethanols and propylene oxide, and embedded in a mixture of Epon and Araldite epoxy resins between Teflon-coated coverslips. After polymerization, the coverslips were removed and the sections were examined with the light microscope. Selected regions of the dorsal horn containing VIP-positive structures were photographed and traced with a drawing tube attachment. These regions were then cut from the flat embedded sections and glued to the surface of a blank Epon block. The blocks were trimmed, and the sections were recut into serial ultrathin sections on an ultramicrotome and mounted onto Formvar-coated, single-slot grids. Both unstained sections and those contrasted with uranyl acetate and lead citrate were studied under a JEM 100B electron microscope.

\section{Results}

\section{Light microscopic observations}

Control absorptions. Specific staining by each antiserum was diminished in a progressive fashion by immunoabsorption with very low concentrations $(0.015$ to $1.5 \mu \mathrm{g} / \mathrm{ml}$ of antiserum) of its respective antigen. For example, VIP immunostaining in the dorsal horn was blocked by more than $50 \%$ with $0.015 \mu \mathrm{g}$ of $\mathrm{VIP} / \mathrm{ml}$; the remaining dorsal horn staining, as well as that in Lissauer's tract and around the central canal, was not abolished until concentrations of $1.5 \mu \mathrm{g} / \mathrm{ml}$ were employed. Preabsorption of the antisera with an excess of heterologous antigens $(150 \mu \mathrm{g} / \mathrm{ml})$ did not indicate any significant cross-reactivity with other peptides in this study. This does not, however, eliminate the possibility that other, as yet unidentified or untested endogenous molecules might contain cross-reactive amino acid sequences.

VIP-like immunoreactivity in the spinal cord. At the light microscopic level, VIP-like immunoreactivity was easily distinguishable as a dense and uniformly distributed $\mathrm{DAB}$ reaction product, imparting a Golgi-like appearance to positively stained elements. A consistent feature of VIP-immunoreactive staining in the spinal cord was its apparent restriction to fiber-like structures. VIP was clearly visualized in long continuous axons, preterminal and terminal arborizations, and in both en passant and terminal enlargements. Within the sacral spinal cord, VIP was characteristically distributed to three regions: the superficial dorsal horn, the intermediate zone, and the gray matter adjacent to the central canal. As Figure 1 illustrates, these regions form a single semicircular area in the transverse plane. The origin, trajectories, and projection patterns of VIP-containing fibers in each of these areas will be described in detail.

VIP was found in many dorsal root fibers, and some fibers occasionally were seen traveling in the dorsolateral funiculus. The densest labeling, however, was concen-

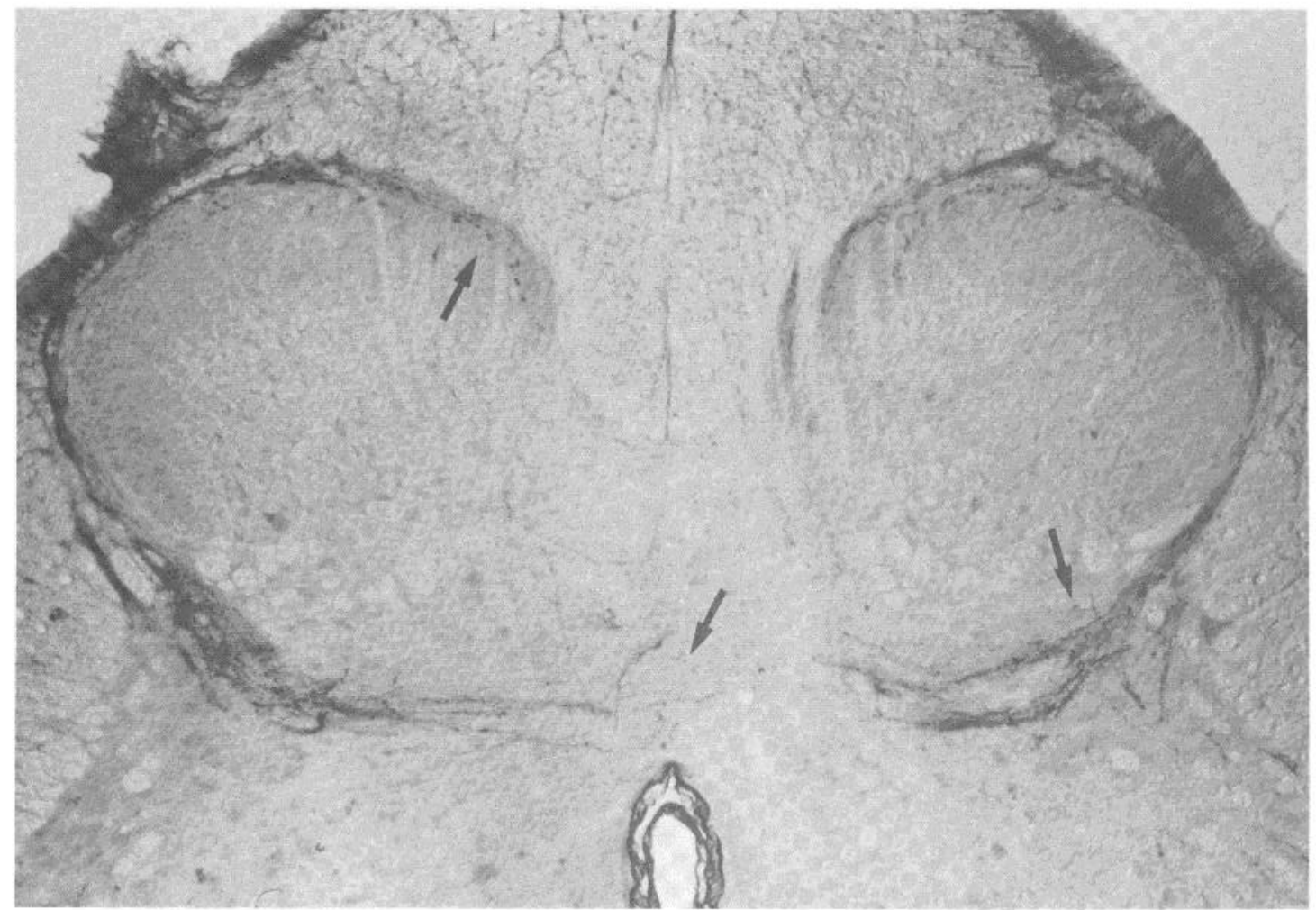

Figure 1. Typical pattern of VIP-like immunoreactivity in a transverse section of sacral spinal cord. Arrows indicate immunoperoxidase staining in laminae I and V to VII, and dorsal to the central canal. Unless noted otherwise, this and subsequent photomicrographs are of $50-\mu \mathrm{m}$ Vibratome sections from the second sacral segment stained according to the PAP technique. 
trated in Lissauer's tract (LT) and represented predominantly longitudinally oriented smooth and varicose axons (Fig. 2A). VIP fibers, apparently originating from $\mathrm{LT}$, formed a thin shell around the dorsal horn, projecting either medially or laterally through the most superficial layer of the dorsal horn, the marginal zone, or Rexed's lamina I (Rexed, 1952) (Figs. 1 and 2, $A$ and $B$ ). Appearing in transverse sections as a thin, dense band in lamina I, the VIP axons contained many beaded varicosities along their lengths and some terminal enlargements. The axons in lamina I did not appear to branch extensively, and only occasional fibers could be seen entering the underlying gray matter (Fig. 2B). When viewed in horizontal sections, the fibers within lamina I were seen to be oriented in both longitudinal and transverse directions (Fig. 2A). The laterally directed band of fibers within lamina I continued ventrally along the edge of the dorsal horn, coalescing into dense periodic bundles as they approached the neck of the dorsal horn. The fibers then turned medially to sweep through the most ventral regions of lamina $V$. This bundling of VIP fibers as they coursed medially through the neck of the dorsal horn can be seen in Figure $3 A$. In this horizontal section through ventral lamina $\mathrm{V}$, dorsolaterally directed fibers have gathered into periodic bundles separated by 150 to $200 \mu \mathrm{m}$, and some fibers have already turned medially.

When viewed in transverse sections, the lateral bundles of VIP fibers characteristically were seen to segregate into three and sometimes two divisions (Figs. 1 and $3 B$ ). A small dorsal branch sweeps upward to form terminal fields in the lateral regions of lamina $\mathrm{V}$, with some fibers projecting further to medial lamina V. A second small branch of the lateral bundles was often observed to follow a more ventrally directed course through lamina VII. Arborizations of the ventrally coursing VIP fibers usually occurred within the region of the sacral parasympathetic nucleus. Often, fibers could be traced further into the ventral horn where they dispersed in a random fashion, and in the rostral sacral cord they appeared to terminate near Onuf's nucleus.

The major division of the lateral bundles was directed primarily at the central canal, with apparent terminal fields being issued along its course through ventral lamina $\mathrm{V}$ and lamina VII. Upon approaching the dorsal edge of the central canal, the bundles began to disperse, losing their periodicity. Extensive VIP arborizations were evident in the posterior commissural gray matter, with many fibers crossing the midline (Fig. $4 A$ ). Often, fibers were seen approaching this region after descending along the medial contour of the dorsal horn. The gray matter surrounding the central canal (lamina X) contained a great number of short, discontinuous VIP-containing profiles, giving the appearance of randomly oriented preterminal axons and terminal enlargements. Of particular interest was the presence of VIP fibers in close association with the ependymal cell layer surrounding the central canal (Fig. $4, A$ and $B$ ). Fibers were usually observed to extend great distances on either side of the ependymal cell layer, and fibers crossing this cell layer were frequently encountered (Fig. $4 B$ ).
VIP-like immunoreactivity in sensory ganglia. The antigenicity of VIP-containing cells in the dorsal root ganglia was very labile and sensitive to many conditions such as perfusion and the degree of postfixation. Immunostaining was thus variable and inconsistent. However, in a limited number of colchicine-pretreated animals, sensory cells in sacral dorsal root ganglia were clearly shown to contain VIP-like immunoreactivity.

As demonstrated in paraffin-embedded tissue (Fig. 5), immunostaining was found predominantly in small and medium-sized cells. For cells sectioned through the nucleus, diameters ranged from $10 \times 20 \mu \mathrm{m}$ to $25 \times 35 \mu \mathrm{m}$. Positively stained axons were observed in close proximity to cell bodies. VIP-positive coiled axonal profiles were often seen, resembling the encapsulated glomerular arrangement of the proximal portions of myelinated fibers described for dorsal root ganglion cells (Ramon y Cajal, 1909).

Deafferented animals. Unilateral deafferentation of the sacral cord ( $\mathrm{S} 1$ to $\mathrm{S} 3$ ) by either dorsal rhizotomy or ganglionectomy resulted in a nearly complete loss of VIP immunostaining in the ipsilateral dorsal horn. Although substantially reduced in number, occasional fibers were detected ipsilateral to the lesion in LT and lamina X, in lumbar through coccygeal levels. Only an occasional fiber could be seen to leave LT and enter the lateral edge of the marginal zone. No differences in VIP staining were detected between the ganglionectomized and rhizotomized animals.

Restriction of VIP to the sacral cord: Comparisons with substance $P(S P)$, somatostatin $(S O M)$, and cholecystokinin-8 (CCK). The distribution of VIP-like immunoreactivity was compared with that of SP, SOM, and CCK in adjacent Vibratome sections from lumbar, sacral, and coccygeal segments (L4 to Co4). SP and CCK were distinctly localized to the superficial dorsal horn (laminae I, II, and outer III), the intermediate gray matter (especially lateral laminae V to VII), and the region dorsal to and surrounding the central canal, and were diffusely distributed within the ventral horn. The distribution of immunoreactivity for SOM in the spinal cord was very similar to that of SP and CCK, with the exception that only the inner portions of lamina II and the outer parts of lamina III were stained.

The density and distribution of SP-, SOM-, and CCKcontaining neuronal elements were constant at all levels examined (Fig. 6). In distinct contrast, the distribution of VIP-containing fibers was almost entirely limited to the gray matter of the sacral segments (Fig. 6). The proportion of LT occupied by VIP fibers progressively decreased both rostrally and caudally until only small bundles persisted at L4 and Co4. Similarly, only isolated VIP terminals could be visualized in lamina $X$ in the most rostral and caudal segments examined.

\section{Electron microscopic observations}

All VIP-containing axons and varicosities examined contained both clear round and large (80 to $100 \mathrm{~nm}$ ) dense core vesicles. The VIP-positive reaction product was frequently seen in the dense core vesicles and, although some dense core vesicles remained unstained, no 

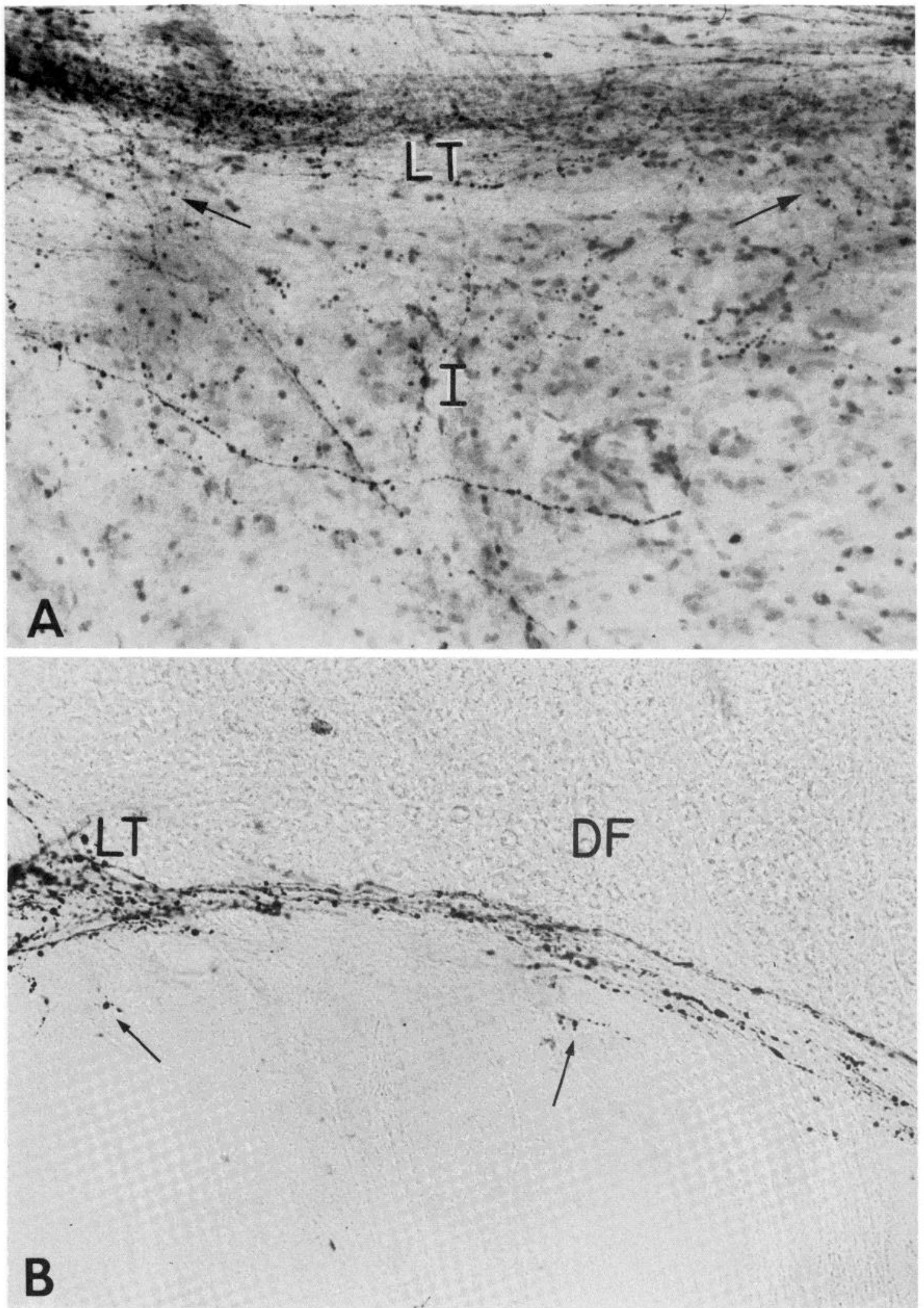

Figure 2. Immunoreactive VIP in horizontal $(A)$ and transverse $(B)$ sections through the superficial dorsal horn. $A$, In this horizontal section, Lissauer's tract $(L T)$ is densely labeled. VIP fibers can be seen leaving LT (arrows) and are oriented in both transverse and longitudinal directions in lamina I (I). $B$, The dense band of VIP fibers confined to lamina I appears to originate from Lissauer's tract $(L T)$. Only occasional fibers enter the outer portions of lamina II (arrows). $D F$, dorsal funiculus. 

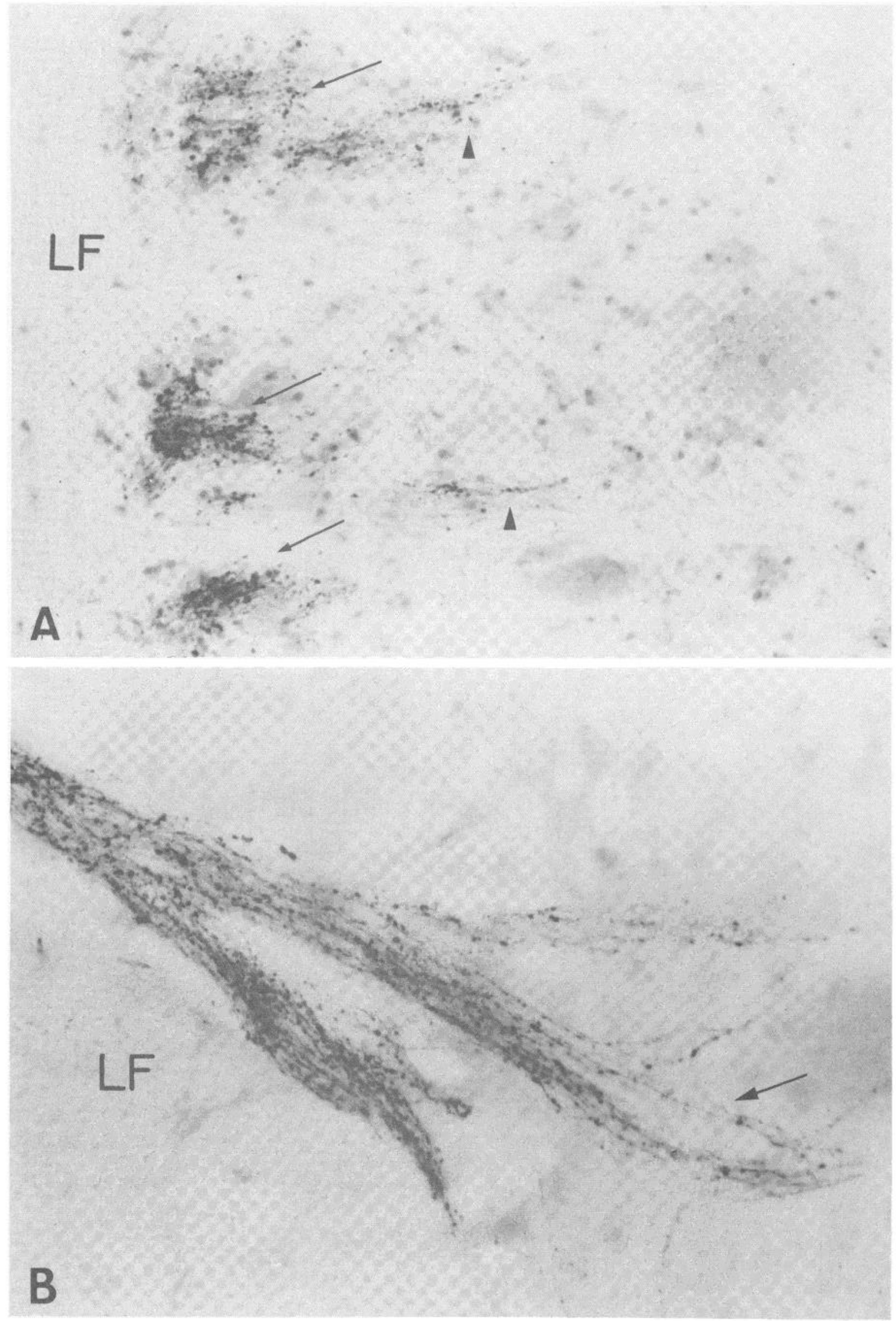

Figure 3. VIP fibers in horizontal $(A)$ and transverse $(B)$ sections through the neck of the dorsal horn. $A$, In this horizontal section through ventral lamina $\mathrm{V}$, three bundles of fibers (arrows) have begun to issue branches (arrowheads) directed medially. Note the periodicity of the bundles that is evident in the horizontal plane. In $B$, the lateral bundle of fibers has separated into three branches as it projects through laminae V to VII. The middle branch of fibers (arrow) is directed at the central canal. $L F$, lateral funiculus. 


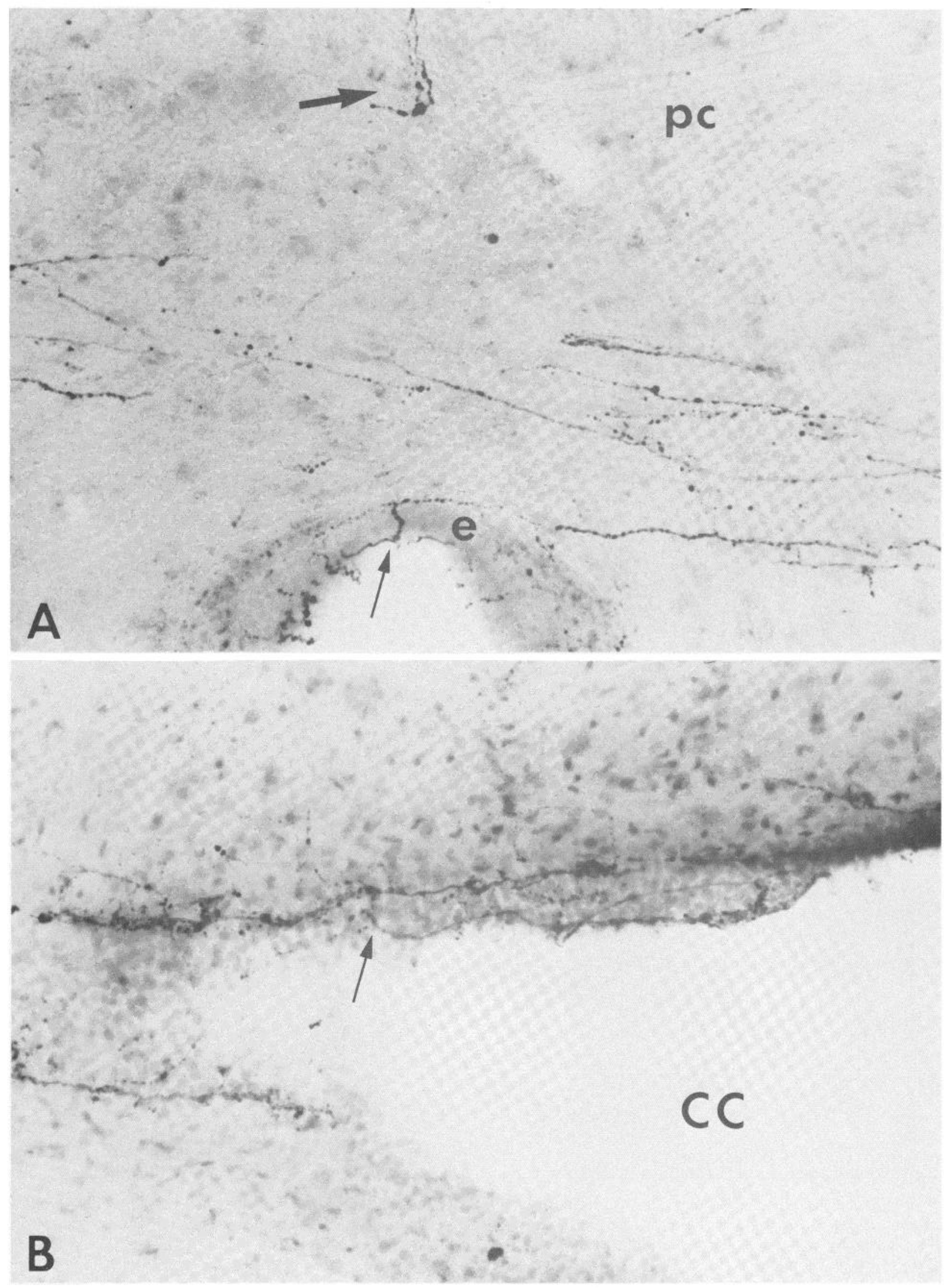

Figure 4. Transverse $(A)$ and horizontal $(B)$ sections showing VIP fibers in the region of the central canal $(C C)$. $A$, Fibers originating from the medial bundle of fibers traveling through lamina I descend along the midline (large arrow). Those originating from the lateral bundles project to the central canal and cross the midline. $B$, Long VIP fibers travel along either side of the ependymal cell layer. Note that VIP fibers (small arrow) often run within the ependymal cell layer $(e)$. pc, posterior commissure. 

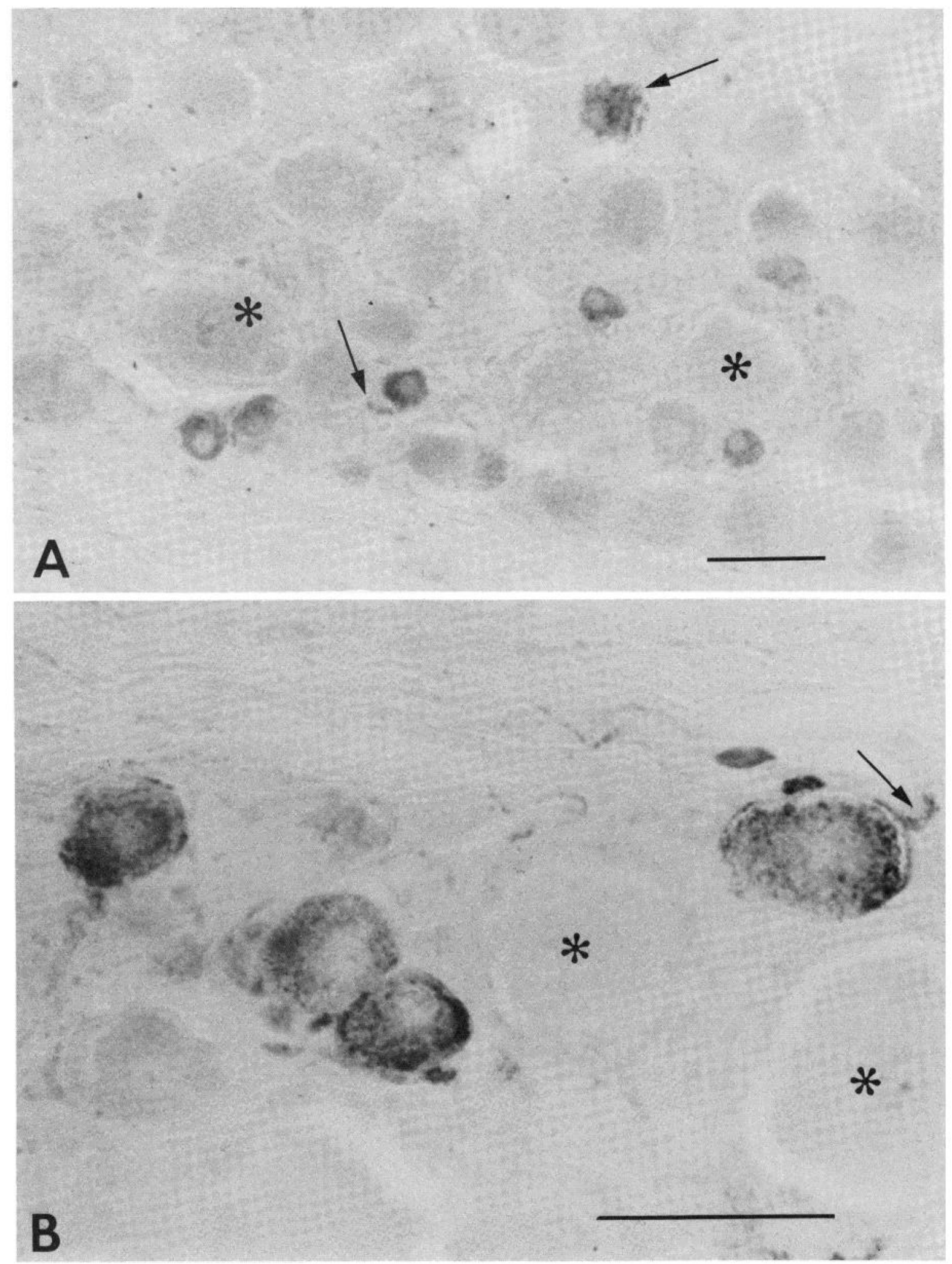

Figure 5. Low $(A)$ and high $(B)$ power photomicrographs of VIP-immunoreactive sensory neurons in paraffin sections of the second sacral dorsal root ganglion. Thick VIP axons (arrows) can often be seen close to the cell bodies. Some large unstained cells are indicated by asterisks. Calibration, $50 \mu \mathrm{m}$.

staining was observed in clear round vesicles. Diffuse staining was often observed in the cytoplasm.

Examination of the dorsal roots revealed fine unmyelinated axons ( 0.3 to $0.5 \mu \mathrm{m}$ diameter) containing both clear synaptic and positively stained dense core vesicles (Fig. 7A). Within the widened neuropile of lamina $\mathrm{I}$ in S2, both fine-caliber interconnecting and enlarged varicose portions of VIP-positive fibers could be seen. Even 


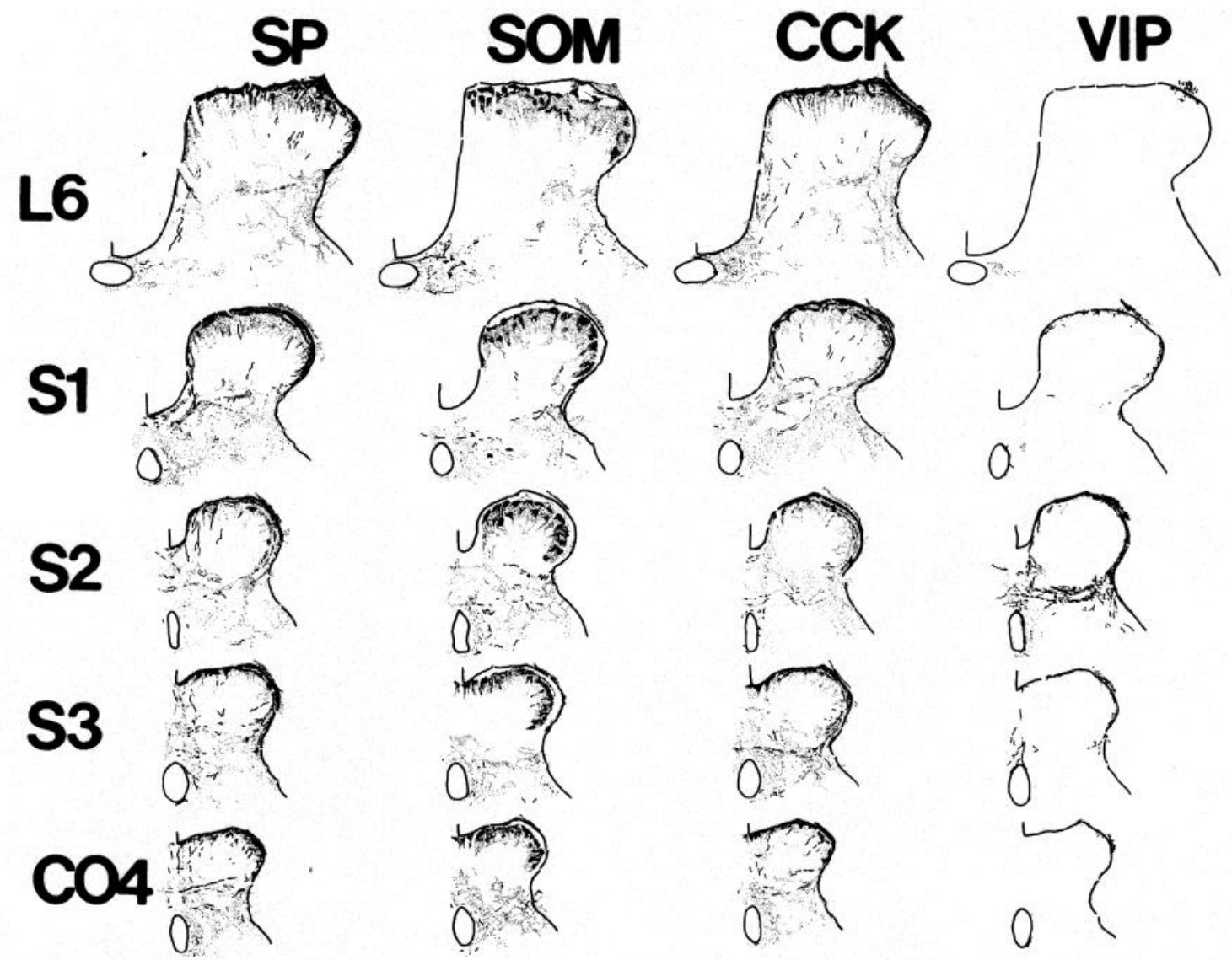

Figure 6. Comparison of the rostrocaudal distribution of SP, SOM, CCK, and VIP immunoreactivity. Each camera lucida drawing is a composite of two adjacent $50-\mu \mathrm{m}$ Vibratome sections.

at low powers of magnification (Fig. $7 B$ ), immunopositive profiles were easily recognizable due to the heavy concentration and staining of dense core vesicles. The varicosities were relatively large, often reaching 4 to 5 $\mu \mathrm{m}$ in their longest dimensions (Fig. $7 C$ ).

Synaptic contacts of VIP-containing fibers with adjacent profiles were rarely observed. When encountered, the most frequent type of interneuronal connection was an axodendritic synapse (Fig. 7, $B$ to $D$ ) exhibiting an accumulation of electron-dense material attached to both pre- and postsynaptic membranes. The clustering of vesicles characteristically associated with most synaptic specializations was not evident in VIP-containing enlargements. This may, however, have been a consequence of the unusually dense packing of both dense core and clear synaptic vesicles in virtually every VIP-positive varicosity examined.

VIP-positive axons were often found in immediate apposition to each other (Fig. $7 C$ ); no membrane specializations were detected between such adjacent profiles. Within the lateral regions of lamina $\mathrm{V}$, the ultrastructure of VIP enlargements was identical to that found in lamina I.

\section{Discussion}

The present study supports suggestions from both radioimmunoassay (Yaksh et al., 1982) and immunohistochemical studies (Lundberg et al., 1978; Hökfelt et al., 1980; Gibson et al., 1981; Basbaum and Glazer, 1982;
Kawatani et al., 1982) that VIP may act as a neurotransmitter/modulator substance in primary afferent neurons. The principal finding of the present study is that, in contrast to the relatively constant density and distribution of SP-, SOM-, and CCK-containing elements in lumbar through coccygeal segments, VIP-immunoreactive fibers are almost completely confined to the sacral spinal cord.

Relationship of VIP to primary afferent neurons. The depletion of immunoreactive VIP fibers within the spinal cord following deafferentation, as well as the demonstration of VIP-containing cell bodies within sacral sensory ganglia, provides direct evidence for the role of VIP as a transmitter/modulator substance in at least some primary sensory neurons. Nearly complete losses of VIP immunoreactivity subsequent to deafferentation have been reported for lumbar spinal cord with radioimmunoassay (Yaksh et al., 1982) and for sacral cord in immunohistochemical studies (Kawatani et al., 1982). The depletion of VIP which we report to follow deafferentation is probably not due to surgical traumas such as ischemic damage (Homma et al., 1979) since no change in Leu-enkephalin immunostaining was detected in adjacent sections.

The VIP fibers in the sacral spinal cord that survived deafferentation (LT and lamina $\mathrm{X}$ ) may have represented incompletely depleted axons containing residual amounts of VIP. Alternatively, they may have been fibers of lumbar or coccygeal origin which were not sectioned 

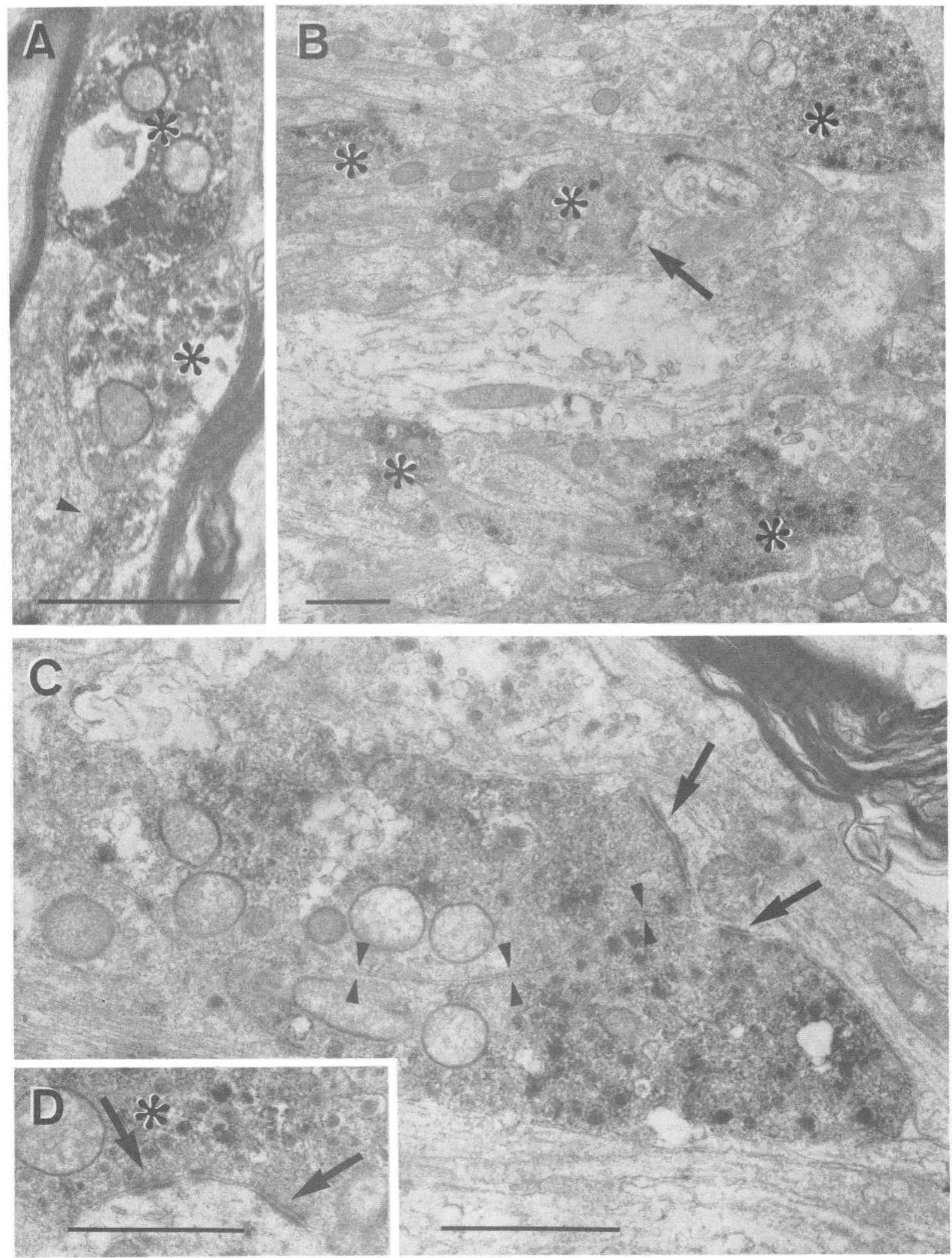

Figure 7. Electron micrographs illustrating ultrastructural localization and synaptic connections of VIP-positive elements. A, Two unmyelinated varicose swellings (asterisks) in a dorsal root filament are flanked by unstained myelinated fibers. The thin portion of another VIP-positive fiber (arrowhead) can be seen. B, Low power micrograph showing VIP-labeled varicosities (asterisks) in lamina I. The arrow indicates synaptic specialization between an enlargement and a small dendritic profile. $C$, Two adjacent VIP-positive varicosities in lamina I (arrowheads indicate membranes in apposition) synapsing (arrows) with the same dendritic profile. $D$, Synaptic specializations (arrows) between a VIP-positive enlargement (asterisk) and a dendritic profile. Calibration, $1 \mu \mathrm{m}$. 
in the sacral deafferentations. Although most primary afferents terminate within one to two segments of their zone of entry, some fibers may extend rostrally or caudally for up to five segments before terminating in the dorsal horn (Heimer and Wall, 1968; Réthelyi et al., 1979). The failure of cervical hemisection to produce a loss of VIP in the spinal cord (Yaksh et al., 1982) argues against the possibility that long descending fibers contribute to staining that survives deafferentation.

The early reports of VIP in some small sensory neurons (Lundberg et al., 1978) have been extended by our descriptions to include some medium-sized dorsal root ganglion cells as well. Furthermore, visualization of VIP axons in the sensory ganglia indicates fiber diameters consistent with both unmyelinated and thinly myelinated afferent fibers.

Distribution of VIP fibers in the spinal cord. VIP immunoreactivity in the spinal cord was first reported as being quite sparse (Loren et al., 1979) and later was described as being localized to the superficial dorsal horn and lamina X (Gibson et al., 1981; Hökfelt et al., 1982). It was fortuitous that our studies were initiated in the sacrococcygeal spinal cord, for it soon became apparent that the greatest density of VIP-containing fibers existed within the sacral segments. The distribution of these fibers is much more extensive than previously described. VIP fibers in the sacral segments are characteristically localized in the marginal zone, laminae V to VII, and the gray matter dorsal to and surrounding the central canal.

The present study confirms the spinal distributions of fibers containing SP (Hökfelt et al., 1975a, b), SOM (Elde et al., 1978; Hunt et al., 1981), and CCK (Larsson and Rehfeld, 1979; Maderdrut et al., 1982) reported by others and is thus not described in great detail. However, the relatively constant density and distribution patterns of these three peptides in lumbar through coccygeal segments indicates that the confinement of VIP immunoreactivity predominantly within sacral segments is not a consequence of experimental procedures such as incomplete perfusion of coccygeal segments. 'The nearly complete restriction of VIP to sacral segments reflects an actual preponderance of VIP-immunoreactive elements.

The possibility remains that the restriction of VIP to sacral segments is a reflection of concentration differences of VIP within individual fibers. In other words, similar numbers of actual VIP fibers may exist in other than sacral segments, but the concentration of peptide is below the level of detectability of the immunohistochemical techniques used in the present study. It is also conceivable that different molecular forms of the peptide are present in peripheral nerves associated with lumbar, sacral, and coccygeal spinal segments. Larsson et al. (1979) concluded that the authentic octacosapeptide VIP is localized only to neuronal tissue, and Dimaline and Dockray (1978) reported that some immunoreactive VIP components distinct from that corresponding to authentic VIP are localized to endocrine cells. Others have suggested, however, that molecular variants as well as authentic VIP are to be found in neural tissue (Dimaline et al., 1980). Thus it is conceivable that the antiserum used in the present study recognizes VIP immunoreactivity in the sacral spinal cord that is distinct from that of other molecular forms of VIP in nearby segments.
Ultrastructure of VIP fibers. Subcellular fractionation studies have indicated a vesicular localization of VIP in both the central (Emson et al., 1978) and peripheral (Lundberg et al., 1981) nervous systems. This has been confirmed by the immunohistochemical demonstration of VIP in large dense core vesicles within nerve terminals in the gut (Larsson, 1977; Sundler et al., 1980) and the submandibular gland (Johansson and Lundberg, 1981). Our report of VIP-containing dense core vesicles in nerve endings that also contain smaller clear vesicles is in agreement with these works.

The most charactcristic features of VIP-containing enlargements within the spinal cord are their large size and the frequent occurrence of dense core vesicles. Similar axonal profiles in the monkey dorsal horn were labeled as synaptic profiles with large granular vesicles, or LGV profiles (Ralston, 1979). The low incidence of synaptic contacts made by VIP enlargements is in accord with the observations of Pelletier et al. (1981) who found that no more than one-half of the VIP-positive axons examined in the rat brain participated in synapses. The possibility of humoral (nonsynaptic) mediation of neuronal activity by VIP-containing fibers should be considered for the spinal cord as well. The lack of clustering of vesicles at synaptic sites in VIP enlargements and the attachment of electron-dense material to both sides of the synaptic cleft make these synapses unique among synapses described in the spinal gray matter.

Possible functional aspects of VIP in the sacral spinal cord. One indication of the functional significance of VIP in the spinal cord may be reflected by the remarkable similarity between the distribution of VIP fibers and pelvic nerve visceral afferent fibers, both in their distribution patterns within the gray matter and in their virtual restriction to the sacral cord. In a very detailed study, Morgan et al. (1981) utilized the transganglionic transport of horseradish peroxidase applied to the pelvic nerve to determine the spinal terminations of visceral afferents. Pelvic nerve visceral afferent fibers distributed from L'I to form lateral and medial collateral pathways, similar to the lateral and medial trajectories of VIP fibers through lamina I. As is the case for VIP fibers, the lateral visceral collateral pathway curves around the lateral edge of the dorsal horn to project to laminae V to VII and to the regions of the posterior commissure and lamina $\mathrm{X}$ where it arborizes in close proximity to the projection from the medial collateral pathway. It is impressive that both VIP immunoreactivity and the spinal terminations of pelvic nerve afferents are largely confined to the sacral segments. The striking similarities between the distribution pattern of VIP fibers and the spinal terminations of the pelvic nerve within the sacral segments probably reflect the presence of VIP immunoreactivity in some afferent fibers from the pelvic viscera.

The presence of VIP in dorsal root ganglion cells similar in size to those innervating the pelvic viscera supports this contention. Sensory ganglion cells whose axons travel in the pelvic nerve are mostly of the smalldiameter population, having average diameters of $23 \times$ $32 \mu \mathrm{m}$ (Morgan et al., 1981), and those with afferent fibers innervating only the bladder have an average diameter of $30 \mu \mathrm{m}$ (Appelbaum et al., 1980). The diameters of VIP-containing sensory cells are in keeping with stud- 
ies characterizing the pelvic nerve as being composed of predominantly thinly myelinated and unmyelinated axons (Langley and Anderson, 1896; Hulsebosch and Coggeshall, 1981). In agreement is a preliminary report demonstrating the presence of VIP in some sensory ganglion cells labeled by a retrograde tracer applied to the pelvic nerve (Kawatani et al., 1982).

The presence of VIP in small sensory neurons and afferent fibers as well as the characteristic distribution of these fibers to the superficial dorsal horn, lamina V, and the regions near the central canal raise the possibility that VIP fibers play a role in nociceptive function. Nociceptive primary afferents are well represented within the populations of unmyelinated and thinly myelinated sensory fibers (Iggo, 1962; Bessou and Perl, 1969; Burgess and Perl, 1967). The spinal distribution of thinly myelinated high threshold mechanoreceptors from both cutaneous (Light and Perl, 1979) and subcutaneous (Mense et al., 1981) structures has been described in detail. These thinly myelinated nociceptors characteristically terminate in laminae I and $\mathrm{V}$ and the gray matter dorsal to and surrounding the central canal, that is, regions that receive dense projections of VIP fibers. Given the similar projection patterns of the myelinated nociceptors, visceral afferents, and VIP fibers, it is tempting to speculate that VIP is a transmitter candidate for nociceptive afferents innervating the viscera.

However, there are many dissimilarities in morphology and ultrastructure between VIP-containing fibers and myelinated somatic nociceptive afferents. All VIP-positive axons examined in the dorsal roots were unmyelinated. VIP fibers displayed great numbers of closely spaced en passant varicosities ranging in size up to $5 \mu \mathrm{m}$, and lengths of axon were seldom free of enlargements. On the other hand, myelinated nociceptors exhibited smaller-sized enlargements ( 1.5 to $2.5 \mu \mathrm{m}$ ), mostly near terminal arborizations (Light and Perl, 1979; Réthelyi et al., 1982). Furthermore, en passant and terminal enlargements of myelinated nociceptors were densely filled with clear spherical synaptic vesicles and participated in simple axodendritic contacts as well as both pre- and postsynaptic arrangements in glomeruli (Réthelyi et al., 1982). In contrast, VIP enlargements contained both clear round and large dense core vesicles and were observed to make only axodendritic synapses. Thus, if visceral nociceptive afferent fibers contain VIP, the morphology of their central axons differs greatly from that of somatic myelinated nociceptors.

VIP-containing fibers project to laminae I and V and the gray matter near the central canal, three regions known to contain cell bodies and processes of nociceptive spinal neurons (Wall, 1960, 1967; Hillman and Wall, 1969; Christensen and Perl, 1970; Light et al., 1979; Honda and Perl, 1981). Rather than being related to nociceptive primary afferents, it seems likely that projections of VIP fibers, possibly of visceral origin, provide a basis for the convergence of somatic nociceptive and visceral afferent impulses. Several descriptions of such somatovisceral convergence, often in lamina V, have been reported (Pomeranz et al., 1968; Selzer and Spencer, 1969; Foreman et al., 1981; Milne et al., 1981).
In conclusion, our data show that in lumbar through coccygeal segments, VIP immunoreactivity is mostly confined to a population of primary afferents terminating in the sacral spinal cord. Based on similarities between the distribution patterns of both VIP fibers and pelvic visceral afferents within the spinal gray matter, and their nearly complete restriction to the sacral cord along the rostrocaudal axis, it is suggested that VIP is contained in many pelvic visceral afferent fibers. Furthermore, it is proposed that VIP fibers contribute to the convergence of information from somatic and pelvic visceral structures.

Note Added in Proof. Since the submission of this material for publication, two groups have reported similar results in several respects to those of the present investigation (Basbaum and Glazer, 1983; de Groat et al., 1983).

\section{References}

Applebaum, A. E., W. H. Vance, and R. E. Coggeshall (1980) Segmental localization of sensory cells that innervate the bladder. J. Comp. Neurol. 192: 203-211.

Basbaum, A. I., and E. J. Glazer (1982) Is VIP another candidate neurotransmitter of primary afferent nociceptors? In Proceedings of the American Pain Society, p. 48, Miami, FL.

Basbaum, A. I., and E. J. Glazer (1983) Immunoreactive vasoactive intestinal polypeptide is concentrated in the sacral spinal cord: A possible marker for pelvic visceral afferent fibers. Somatosensory Res. 1: 69-82.

Besson, J., W. Rotsztejn, M. Laburthe, J. Epelbaum., A. Beaudet, C. Kordon, and G. Rosselin (1979) Vasoactive intestinal polypeptide (VIP): Brain distribution, subcellular localization and effect of deafferentation of the hypothalamus in male rats. Brain Res. 165: 79-85.

Bessou, P., and E. R. Perl (1969) Response of cutaneous sensory units with unmyelinated fibers to noxious stimuli. J. Neurophysiol. 32: 1025-1043.

Bryant, M. G., S. R. Bloom, J. M. Polak, R. H. Albuquerque, I. Modlin, and A. G. E. Pearse (1976) Possible dual role for vasoactive intestinal peptide as gastrointestinal hormone and neurotransmitter substance. Lancet 1: 991-993.

Burgess, P. R., and E. R. Perl (1967) Myelinated afferent fibers responding specifically to noxious stimulation of the skin. J. Physiol. (Lond.) 190: 542-562.

Christensen, B. N., and E. R. Perl (1970) Spinal neurons specifically excited by noxious or thermal stimuli: Marginal zone of the dorsal horn. J. Neurophysiol. 33: 293-307.

Costa, M., J. B. Furness, R. Buffa, and S. I. Said (1980) Distribution of enteric nerve cell bodies and axons showing immunoreactivity for vasoactive intestinal polypeptide in the guinea-pig intestine. Neuroscience 5: 587-596.

de Groat, W. C., M. Kawatani, T. Hisamitsu, I. Lowe, C. Morgan, J. Roppolo, A. M. Booth, I. Nadelhaft, D. Kuo, and $\mathrm{K}$. Thor (1983) The role of neuropeptides in the sacral autonomic reflex pathways of the cat. J. Autonomic Nervous System 7: 339-350.

Dimaline, R., and G. J. Dockray (1978) Multiple immunoreactive forms of vasoactive intestinal peptide in human colonic mucosa. Gastroenterology 75: 387-392.

Dimaline, R., C. Vaillant, and G. J. Dockray (1980) The use of region-specific antibodies in the characterization of vasoactive intestinal polypeptide-like substances in the rat gastrointestinal tract. Regul. Pept. 1: 1-16.

Elde, R., T. Hökfelt, O. Johansson, M. Schultzberg, S. Efendić, and R. Luft (1978) Cellular localization of somatostatin. 
Metabolism 27: 1151-1159

Emson, P. C., J. Fahrenkrug, O. B. Schaffalitzky de Muckadell, T. M. Jessel, and L. L. Iversen (1978) Vasoactive intestinal polypeptide (VIP): Vesicular localization and potassium evoked release from rat hypothalamus. Brain Res. 143: 174178.

Emson, P. C., J. Fahrenkrug, and E. G. S. Spokes (1979) Vasoactive intestinal polypeptide (VIP): Distribution in normal human brain and in Huntington's disease. Brain Res. 173: $174-178$.

Foreman, R. D., M. B. Hancock, and W. D. Willis (1981) Responses of spinothalamic tract cells in the thoracic spinal cord of the monkey to cutaneous and visceral inputs. Pain 11: 149-162.

Fuxe, K., T. Hökfelt, S. I. Said, and V. Mutt (1977) Vasoactive intestinal polypeptide and the nervous system: Immunohistochemical evidence for localization in central and peripheral neurons, particularly intracortical neurons of the cerebral cortex. Neurosci. Lett. 5: 241-246.

Giachetti, A., and S. I. Said (1979) Axonal transport of vasoactive intestinal peptide in sciatic nerve. Nature 281: 574575.

Gibson, S. J., J. M. Polak, S. R. Bloom, and P. D. Wall (1981) The distribution of nine peptides in rat spinal cord with special emphasis on the substantia gelatinosa and on the area around the central canal (lamina X). J. Comp. Neurol. 201: 65-79.

Heimer, L., and P. D. Wall (1968) The dorsal root distribution to the substantia gelatinosa of the rat with a note on the distribution in the cat. Exp. Brain Res. 6: 89-99.

Hillman, P., and P. D. Wall (1969) Inhibitory and excitatory factors influencing the receptive fields of lamina 5 spinal cord cells. Exp. Brain Res. 9: 284-306.

Hökfelt, T., J. -O. Kellerth, G. Nilsson, and B. Pernow (1975a) Experimental immunohistochemical studies on the localization and distribution of substance $\mathrm{P}$ in cat primary sensory neurons. Brain Res. 100: 235-252.

Hökfelt, T., J. O. Kellerth, G. Nilsson, and B. Pernow (1975b) Substance P: Localization in the central nervous system and in some primary sensory neurons. Science 190: 889-890.

Hökfelt, T., O. Johansson, A. Ljundgdahl, J. M. Lundberg, and M. Schultzberg (1980) Peptidergic neurones. Nature 284: 515-521.

Hökfelt, T., M. Schultzberg, J. M. Lundberg, K. Fuxe, J. Fahrenkrug, and S. I. Said (1982) Distribution of vasoactive intestinal polypeptide in the central and peripheral nervous systems as revealed by immunohistochemistry. In Vasoactive Intestinal Peptide, S. I. Said, ed., pp. 65-90, Raven Press, New York.

Homma, S., T. Suzuki, S. Murayama, and M. Otsuka (1979) Amino acid and substance $P$ contents in spinal cord of cats with experimental hind-limb rigidity produced by occlusion of spinal cord blood supply. J. Neurochem. 32: 691-698.

Honda, C. N. (1982) Preferential immunohistochemical localization of vasoactive intestinal polypeptide (VIP) in the sacral spinal cord of the cat. Soc. Neurosci. Abstr. 8: 585.

Honda, C. N., and E. R. Perl (1981) Properties of neurons in lamina $\mathrm{X}$ and the midline dorsal horn of the sacrococcygeal spinal cord of the cat. Soc. Neurosci. Abstr. 7: 191.

Hulsebosch, C. E., and R. E. Coggeshall (1981) Origin of axons in the bladder nerves. Soc. Neurosci. Abstr. 7: 214.

Hunt, S. P., J. S. Kelly, P. C. Emson, J. R. Kimmel, R. J. Miller, and J-Y. Wu (1981) An immunohistochemical study of neuronal populations containing neuropeptides or $\gamma$-aminobutyrate within the superficial layers of the rat dorsal horn. Neuroscience 6: 1883-1898.

Iggo, A. (1962) Non-myelinated visceral, muscular and cuta- neous afferent fibres and pain. In The Assessment of Pain in Man and Animals, C. A. Keele and R. Smith, eds., pp. 74-87, Livingstone, London.

Johansson, O., and J. M. Lundberg (1981) Ultrastructural localization of VIP-like immunoreactivity in large dense-core vesicles of "cholinergic-type" nerve terminals in cat exocrine glands. Neuroscience 6: 847-862.

Kawatani, M., I. Lowe, C. Morgan, I. Nadelhaft, S. Erdman, and W. C. DeGroat (1982) Vasoactive intestinal polypeptide (VIP) in primary afferent projections to the sacral spinal cord of the cat. Soc. Neurosci. Abstr. 8: 585.

Kumazawa, T., and E. R. Perl (1976) Differential excitation of dorsal horn marginal and substantia gelatinosa neurons by primary afferent units with fine (A $\delta$ and C) fibers. In Sensory Functions of the Skin in Primates, Y. Zotterman, ed., pp. 6788, Pergamon Press, Oxford.

Langley, J. N., and H. K. Anderson (1896) The innervation of the pelvic and adjoining viscera. Part VI. Histological and physiological observations upon the effects of section of the sacral nerves. J. Physiol. (Lond.) 20: 372-384.

Larsson, L. -I. (1977) Ultrastructural localization of a new neuronal peptide (VIP). Histochemistry 54: 173-177.

Larsson, L. -I., and J. F. Rehfeld (1979) Localization and molecular heterogeneity of cholecystokinin in the central and peripheral nervous system. Brain Res. 165: 201-218.

Larsson, L. -I., J. Fahrenkrug, O. Schaffalitzky de Muckadell, F. Sundler, R. Håkanson, and J. F. Rehfeld (1976) Localization of vasoactive intestinal polypeptide (VIP) to central and peripheral neurons. Proc. Natl. Acad. Sci. U. S. A. 73: 31973200 .

Larsson, L. -I., J. M. Polak, R. Buffa, R. Sundler, and E. Solcia (1979) On the immunocytochemical localization of the vasoactive intestinal polypeptide. J. Histochem. Cytochem. 27: 936-938.

Light, A. R., and E. R. Perl (1979) Spinal termination of functionally identified primary afferent neurons with slowly conducting myelinated fibers. J. Comp. Neurol. 186: 133150 .

Light, A. R., D. L. Trevino, and E. R. Perl (1979) Morphological features of functionally defined neurons in the marginal zone and substantia gelatinosa of the spinal dorsal horn. J. Comp. Neurol. 186: 151-171.

Loren, I., P. C. Emson, J. Fahrenkrug, A. Björklund, J. Alumets, R. Håkanson, and F. Sundler (1979) Distribution of vasoactive intestinal polypeptide in the rat and mouse brain. Neuroscience 4: 1953-1976.

Lundberg, J. M., T. Hökfelt, G. Nilsson, L. Terenius, J. Rehfeld, R. Elde, and S. I. Said (1978) Peptide neurons in the vagus, splanchnic and sciatic nerves. Acta Physiol. Scand. 104: 499501.

Lundberg, J. M., G. Fried, J. Fahrenkrug, B. Holmstedt, T. Hökfelt, H. Lagercrantz, G. Lundgren, and A. Änggård (1981) Subcellular fractionation of cat submandibular gland: Comparative studies on the distribution of acetylcholine and vasoactive intestinal polypeptide (VIP). Neuroscience 6: 1001-1010.

Maderdrut, J. L., T. L. Yaksh, P. Petrusz, and V. L. W. Go (1982) Origin and distribution of cholecystokinin-containing nerve terminals in the lumbar dorsal horn and nucleus caudalis of the cat. Brain Res. 243: 363-368.

Mense, S., A. R. Light, and E. R. Perl (1981) Spinal terminations of subcutaneous high threshold mechanoreceptors. In Spinal Cord Sensation, A. G. Brown and M. Réthelyi, eds., pp. 79-86, Scottish Academic Press, Edinburgh.

Metz, C. B., A. M. Kavookjian, and A. R. Light (1983) Techniques for HRP intracellular staining of neural elements for light and electron microscopic analyses. J. Electrophysiol. 
Tech. 9: 151-163.

Milne, R. J., R. D. Foreman, G. J. Giesler, Jr., and W. D. Willis (1981) Convergence of cutaneous and pelvic visceral nociceptive inputs onto primate spinothalamic neurons. Pain 11: 163-183.

Morgan, C., I. Nadelhaft, and W. C. de Groat (1981) The distribution of visceral primary afferents from the pelvic nerve to I issauer's tract and the spinal gray matter and its relationship to the sacral parasympathetic nucleus. J. Comp. Neurol. 201: 415-440.

Pelletier, G., R. Leclarc, R. Puviani, and J. M. Polak (1981) Electron immunocytochemistry in vasoactive intestinal peptide (VIP) in the rat brain. Brain Res. 210: 356-360.

Petrusz, P., P. DiMeo, P. Ordronneau, C. Weaver, and D. Keefer (1975) Improved immunoglobulin-enzyme bridge method for light microscopic demonstration of hormonecontaining cells of the rat adenohypophysis. Histochemistry 46: 9-26.

Pomeranz, B., P. D. Wall, and W. V. Weber (1968) Cord cells responding to fine myelinated afferents from viscera, muscle and skin. J. Physiol. (Lond.) 199: 511-532.

Ralston, H. J., III (1979) The fine structure of laminae I, II and III of the macaque spinal cord. J. Comp. Neurol. 184: 619-642.

Ramon y Cajal, S. (1909) Histologie du Systeme Nerveux de l'IIomme et des Vertebres, Vol. 1, Maloine, Paris.

Réthelyi, M., D. L. Trevino, and E. R. Perl (1979) Distribution of primary afferent fibers within the sacrococcygeal dorsal horn: An autoradiographic study. J. Comp. Neurol. 185: 603-
622.

Réthelyi, M., A. R. Light, and E. R. Perl (1982) Synaptic complexes formed by functionally defined primary afferent units with fine myelinated fibers. J. Comp. Neurol. 207: 381393.

Rexed, B. (1952) The cytoarchitectonic organization of the spinal cord in the cat. J. Comp. Neurol. 96: 415-466.

Said, S. I., and V. Mutt (1970) Polypeptide with broad biological activity: Isolation from small intestine. Science 169: 12171218.

Said, S. I., and R. N. Rosenberg (1976) Vasoactive intestinal polypeptide: Abundant immunoreactivity in neural cell lines and normal nervous tissue. Science 192: 907-908.

Selzer, M., and W. A. Spencer (1969) Convergence of visceral and cutaneous afferent pathways in the lumbar spinal cord. Brain Res. 14: 331-348.

Sternberger, L. A. (1979) Immunocytochemistry, Ed. 2, p. 104, John Wiley \& Sons, Inc., New York.

Sundler, F., R. Håkanson, and S. Leander (1980) Peptidergic nervous systems in the gut. Clin. Gastroenterol. 9: 517-543.

Wall, P. D. (1960) Cord cells responding to touch, damage, and temperature of skin. J. Neurophysiol. 23: 197-210.

Wall, P. D. (1967) The laminar organization of dorsal horn and effects of descending impulses. J. Physiol. (Lond.) 188: 403423.

Yaksh, T. L., E. O. Abay, II, and V. L. W. Go (1982) Studies on the location and release of cholecystokinin and vasoactive intestinal peptide in rat and cat spinal cord. Brain Res. 242: 279-290. 